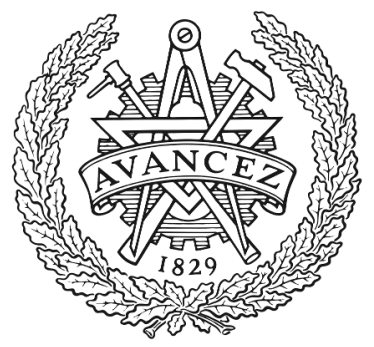

CHALMERS

UNIVERSITY OF TECHNOLOGY

\title{
Multifunctional graphene oxide/biopolymer composite aerogels for microcontaminants removal from drinking water
}

Downloaded from: https://research.chalmers.se, 2023-04-26 12:11 UTC

Citation for the original published paper (version of record):

Kovtun, A., Campodoni, E., Favaretto, L. et al (2020). Multifunctional graphene oxide/biopolymer composite aerogels for microcontaminants removal from drinking water. Chemosphere, 259(November 2020).

http://dx.doi.org/10.1016/j.chemosphere.2020.127501

N.B. When citing this work, cite the original published paper. 


\section{Multifunctional graphene oxide/biopolymer composite aerogels for}

\section{microcontaminants removal from drinking water}

Alessandro Kovtun, ${ }^{\mathrm{a},}$ Elisabetta Campodoni, ${ }^{\mathrm{b}},+$ Laura Favaretto, ${ }^{\mathrm{a}}$ Massimo Zambianchi, ${ }^{\mathrm{a}}$ Anastasio Salatino, ${ }^{\mathrm{c}}$ Stefano Amalfitano, ${ }^{\mathrm{c}}$ Maria Luisa Navacchia, ${ }^{\mathrm{a}}$ Barbara Casentini, ${ }^{\mathrm{c}}$ Vincenzo Palermo, ${ }^{\mathrm{a}, \mathrm{d},{ }^{*}}$ Monica Sandri, ${ }^{\mathrm{b}}$ Manuela Melucci ${ }^{\mathrm{a},{ }^{\text {* }}}$

Consiglio Nazionale delle Ricerche (CNR, Italy), a) Institute of Organic Synthesis and Photoreactivity (CNR-ISOF) via Piero Gobetti 101, 40129 Bologna, Italy, b) Institute of Science and Technology for Ceramics (CNR-ISTEC) Via Granarolo, 64 - 48018 Faenza (RA), c) Water Research Institute (CNR-IRSA) Via Salaria Km 29,300 C.P. 10-00015 Monterotondo Stazione (RM), d) Chalmers University of Technology, Industrial and Materials Science, Hörsalsvägen 7A, SE-41296 Goteborg, Sweden.

\section{Abstract}

Due to water depletion and increasing level of pollution from standard and emerging contaminants, the development of more efficient purification materials and technology for drinking water treatment is a crucial challenge to be addressed in the near future. Graphene oxide (GO) has been pointed as one of the most promising materials to build structure and devices for new adsorbents and filtration systems. Here, we analyzed two types of GO doped 3D chitosan-gelatin aerogels with GO sheets embedded in the bulk or deposited on the surface. Through combined structural characterization and adsorption tests on selected proxies of drinking water micropollutants, we compared both GO-embedded and GO-coated materials and established the best architecture for achieving enhanced removal efficiency toward contaminants in water. To evaluate the best configuration, we studied the adsorption capacity of both systems on two organic molecules (i.e., 
27 fluoroquinolonic antibiotics ofloxacin and ciprofloxacin) and a heavy metal (lead $\mathrm{Pb}^{2+}$ ) of great 28 environmental relevance and with already proved high affinity for $\mathrm{GO}$. The $\mathrm{Pb}$ monolayer maximum adsorption capacity $\mathrm{q}_{\max }$ was $11.1 \mathrm{mg} / \mathrm{g}$ for embedded $\mathrm{GO}$ aerogels and $1.5 \mathrm{mg} / \mathrm{g}$ in coated GO-ones. Only minor differences were found for organic contaminants between coating and embedding approaches with an adsorption capacity of 5-8 $\mathrm{mg} / \mathrm{g}$ and no adsorption was found for chitosan-gelatin control aerogels without GO. Finally, potential antimicrobial effects were found particularly for the GO-coated aerogels materials, thus corroborating the multifunctionality of the newly developed porous structures.

Keywords. Graphene oxide aerogels, chitosan, drinking water, lead, antibiotics, adsorption

\section{Introduction}

39 Drinking water contamination is a major concern to be rapidly faced with new materials and technologies. More than 30000 chemicals with a variety of chemical structures and unknown longterm toxicity and effect on the ecosystems are introduced every day into the market and directly or indirectly released into our water resources. Due to the lack of efficiency for a complete removal of emerging contaminants by wastewater treatment technologies, their occurrence in drinking water is not uncommon (Riva et al., 2018; Lapworth et al., 2012). This creates an urgent need to design versatile purification systems (i.e. adsorbent, membranes) with wider selectivity, enhanced efficiency, which can be regenerated to tackle the removal of a wide range of contaminants in a sustainable way (Joseph et al., 2017). The recently proposed recast of the European drinking water Directive 98/83/EC (Recast, (2017) 753, 2017), includes revision of the current limits for a wide list

49 of contaminants including organic molecules, metal ions and cultivable index microbial pathogens 50 (Annex, (2017), 753). The concentration limits for some toxic substances have been reduced (i.e., $51 \mathrm{~Pb}$ and $\mathrm{Cr}$ ), some pollutants of raising concern have been added (i.e., perfluorinated compounds, 
chlorate and chlorite, endocrine disrupting compounds) and proposed microbiological assessment

53 methods were updated.

54 Moreover, emerging chemical contaminants, hardly removed by conventional treatment, represent additional threats for direct human consumption of treated waters (Lapworth et al., 2012; Hartmann et al., 2018). In Europe, the Directive 2008/105/EC introduced Environmental Quality Standards for a number of emerging pollutants to protect human and environmental health. The updated Watch List includes organic contaminants, such as pesticides, pharmaceuticals, perfluorinated compounds, personal healthcare products, and heavy metals (cadmium, lead, mercury and nickel) (EU Watchlist). Along with chemicals, there are also major risks associated with the occurrence of microbial pathogens and antimicrobial resistant microorganisms even at very low concentrations, which are known to negatively influence the provision of water for drinking purposes (Nappier et al., 2018).

Water contaminants are currently removed by different technologies that often need to be combined to guarantee the required level of purity, thus urgently calling for the development of multifunctional materials possibly capable of simultaneous removal of different species of contaminants.

Due to their high specific surface area and surface reactivity as compared to conventional bulk materials, nanomaterials show high potential in controlling heavy metals, organic pollutants and microorganism removal in drinking water (Simeonidis et al., 2016; Xu et al., 2018). In particular, graphene oxide (GO) holds great potential in this field (Ersan et al., 2017; Wang et al., 2015; Sweetman et al., 2017; Baig et al., 2019). Indeed, GO represents a scaffold with $\pi-\pi$ interactions, hydrophobic interactions as activated carbons, but it also has polar chemical oxygen

74 based chemical groups promoting higher hydrophilicity, electrostatic interaction, higher 75 processability in water (Backes et al., 2020). Moreover, graphene-based nanosheets are also potentially ideal materials to intercalate/capture metal ions (Ji et al., 2019; Xu et al., 2017), hence 
opening promising perspectives in batteries and supercapacitors applications (Mukherjeel et al., 2018).

Finally, graphene has been studied also for its antibacterial properties, based on the mechanical disruption and penetration of graphene platelets in the bacterial membrane (Zou et al., 2016). However, despite such outstanding properties, their effect in drinking water has still to be properly evaluated (Westerhoff et al., 2018; Troester et al., 2016). Removal of GO nanosheets from treated water would not be trivial, thus their inclusion in 3D structures is required to avoid side contamination.

Different graphene oxide-based 3D structures have been proposed and some of them have already proved superior adsorption capability compared with Granular Activated Carbon (GAC), the industrial standard for some metal ions and organic compounds (Yousefi et al., 2019). Moreover, covalent chemical modification of the oxygen-based functionalities offers a powerful tool to tune the selectivity of GO based structures (Good et al., 2016). Defining the best approach for supporting $\mathrm{GO}$ on 3D structures is important to maximize the removal efficacy of the final composite. Indeed, the interaction between GO and the organic molecules strongly depend on the exposure of PSU-GO composites adsorption of organic molecules is effective in both embedded (Zambianchi et al., 2017) or coated (Kovtun et al., 2019a; Kovtun et al., 2020) configurations with higher performance for GO coated structures in which the interlayer distance between GO sheets can play a role.

98 Along this line, we consider here gelatin-chitosan (GC) based aerogels (Barrios et al., 2019) specifically designed to host GO and compare two different fabrication approaches, based on the embedding of GO into aerogel or coating of GC. We evaluated mechanical stability, GO release and efficiency of adsorption of the targeted contaminants from water. 
102 Gelatin is a hydrophilic and water-soluble protein polymer, deriving from collagen hydrolysis, then 103 completely biocompatible. Chitosan is a natural cationic polysaccharide, deriving from the 104 deacetilation of chitin, the main component of crustacean's exoskeletons. Both these biopolymers, 105 selected primarily for their chemical properties and ability to form 3D structures, are waste 106 materials of the food industry and due to their plentiful alimentary use, are highly available, low107 cost and suitable to respond to the concept of circular economy. Moreover, chitosan has been 108 widely used in water treatment by itself or as a support of more active compounds (Yang et al., 109 2016) and it is particularly interesting also for its natural antimicrobial activity (Hosseinnejad et al., 110 2016).

111 Chitosan-gelatin blends can be suitably combined and processed by freeze-drying, to achieve 112 aerogels of customised properties in terms of porosity, density, surface area availability and 113 structures. Cross-linking between them have been shown to create irreversible covalent bonds 114 deriving from the reaction between pendant carboxylic and amino groups. Chitosan improves 115 mechanical properties and prevents degradation in water observed for simple blends (Shankar et al., 116 2017; Campodoni et al., 2019; Krishnakumar et al., 2018). Furthermore, due to the exposed amino 117 groups, CG aerogels can interact and react with carboxylic and epoxides groups of GO (Poletti et 118 al., 2020) allowing to obtain stable composite devices that attract great attention in the field of 119 biotechnology (Zhang et al., 2017).

120 To unravel the actual exposure and efficacy of GO in both composites, we perform adsorption test 121 on two organic molecules, ofloxacin and ciprofloxacin, and $\mathrm{Pb}$ ions for whom $\mathrm{GO}$ has already 122 proved good adsorption capacity (Peng et al., 2017; Wan et al., 2016; Zhoun et al., 2015; Wan et 123 al., 2016; Madadrang et al., 2012). Indeed, we recently demonstrated the great affinity of GO for 124 fluoroquinolonic antibiotics that resulted in maximum adsorption capacity $\left(\mathrm{q}_{\max }\right)$ higher than 300 $125 \mathrm{mg} / \mathrm{g}$ for ofloxacin molecule for GO nanosheets (Kovtun et al., 2019a) and of about $31 \mathrm{mg} / \mathrm{g}$ for 126 polysulfone-GO (Kovtun et al., 2019a) composites. Moreover, the removal of Pb by GO aerogel 127 was previously tested and $\mathrm{q}_{\max }$ was calculated to be as high as $158 \mathrm{mg} / \mathrm{g}$ according to Langmuir 
model (Tabrizi et al., 2016). For sake of comparison with previous published data, we used these

129 molecules as references to check if GO was effective for adsorption in the targeted configurations

130 more suitable for drinking water treatments.

131 It should be noted that the selected contaminants are of great environmental concern. Indeed, US-

132 Environmental Protection Agency is keeping a watchful eye onto possible $\mathrm{Pb}$ contamination after 133 water crises induced by Pb contamination into piped waters (Roy et al., 2019; Levallois et al., 2018) 134 and in Europe 98/83/EU Directive for water intended for human consumption is currently under 135 discussion and $\mathrm{Pb}$ concentration now regulated at $10 \mu \mathrm{g} / \mathrm{L}$ is suggested to be lowered at $5 \mu \mathrm{g} / \mathrm{L}$. On 136 the other hand, ofloxacin and ciprofloxacin are fluoroquinolonic antibiotics, with ciprofloxacin 137 included in the EU Watch List (EU Watchlist).. Antibiotics represent one of the emerging 138 contaminants in groundwater (Lapworth et al., 2012), since. they are frequently detected in different 139 aquatic environments within urban water cycles (waste, surface and drinking water (Sanseverino et 140 al., 2018; Pharmaceuticals, 2011) (Patrolecco et al., 2018).

\section{Materials and methods}

\subsection{Synthesis}

144 Type A pig skin gelatin (Gel, G) in powder form (mesh 4, bloom 280) was purchased from 145 Italgelatine (Cuneo, Italy). Low molecular weight chitosan (Chit, C) was supplied by Sigma146 Aldrich (MO, USA). GO was prepared by Hummer method according to previously described 147 procedure (Melucci et al., 2012). High-purity chemical reagents were purchased from Sigma148 Aldrich. Ultrapure water (Milli-Q) was used for all experiments.

\section{Synthesis of Gelatin-Chitosan aerogels as control in the embedding technique (CG-E):}

150 A $2 \% \mathrm{w} / \mathrm{w}$ Gel solution was prepared dissolving $8 \mathrm{~g}$ in $400 \mathrm{~mL}$ of Milli-Q at $45{ }^{\circ} \mathrm{C}$ and a $2 \% \mathrm{w} / \mathrm{w}$ 151 Chit solution was prepared dissolving $3.43 \mathrm{~g}$ in $171.42 \mathrm{~mL}$ of $1 \%$ acetic solution till its complete 152 dissolution. Gel and Chit solutions were blended at room temperature for $15 \mathrm{~min}$ in order to obtain 153 a Gel:Chit ratio of 70:30 and a final blend concentration of $2 \% \mathrm{w} / \mathrm{w}$. 
Blend hydrogel were freeze-dried putting into a specific home-made mould with a copper bottom and plastic wall, to perform a perfect vertical growth of ice crystal and following a specific freezedrying cycle with a controlled freezing ramp $\left(50{ }^{\circ} \mathrm{C} / \mathrm{h}\right)$ until $-40{ }^{\circ} \mathrm{C}$ and with a controlled heating ramp of $5{ }^{\circ} \mathrm{C} / \mathrm{h}$ from $40{ }^{\circ} \mathrm{C}$ to $-10{ }^{\circ} \mathrm{C}$ and to $+15{ }^{\circ} \mathrm{C}$ at $3{ }^{\circ} \mathrm{C} / \mathrm{h}$. Dehydrothermal treatment (DHT) was carried out after freeze-drying to cross-link GC aerogels and improve their stability. Aerogels were introduced into an oven at $100{ }^{\circ} \mathrm{C}$ for $48 \mathrm{~h}$ under vacuum $(0.01 \mathrm{mbar})$.

Synthesis of CGGO-E. A 4\% w/w Gel solution was prepared dissolving $8 \mathrm{~g}$ in $200 \mathrm{~mL}$ of Milli-Q at $45{ }^{\circ} \mathrm{C}$ and a $2 \% \mathrm{w} / \mathrm{w}$ Chit solution was prepared dissolving $3.43 \mathrm{~g}$ in $171.42 \mathrm{~mL}$ of $1 \%$ acetic solution till its complete dissolution. Gel and Chit solutions were blended at room temperature for $15 \mathrm{~min}$ in order to obtain a Gel:Chit weight ratio of 70:30. GO suspension was prepared dispersing $0.572 \mathrm{~g}$ in $228.5 \mathrm{~mL}$ of Milli-Q using a tip sonicator (Sonics, Vibra cell, VCX500, max power 500W, ampl. $40 \%$ for $10 \mathrm{~min}$ ). GO suspension was added in GC blend for $15 \mathrm{~min}$ in order to obtain a final blend concentration of $2 \% \mathrm{w} / \mathrm{w}$ and a GO:blend weight ratio of 5:95. The composite hydrogel GCGO-E was introduced into a specific home-made mould with a copper bottom and plastic wall and, after gelation, was freeze-dried by setting a specific freeze-drying cycle: a freezing ramp of $50{ }^{\circ} \mathrm{C} / \mathrm{h}$, until $-40{ }^{\circ} \mathrm{C}$ and a controlled heating ramp of $5{ }^{\circ} \mathrm{C} / \mathrm{h}$ from $-40{ }^{\circ} \mathrm{C}$ to $-10{ }^{\circ} \mathrm{C}$ and to $15^{\circ} \mathrm{C}$ at $3^{\circ} \mathrm{C} / \mathrm{h}$. The customised mould and process were essential to obtain a perfect vertical growth of ice crystals and thus an aligned structure in the dried composite aerogel. DHT treatment was carried out after freeze-drying to cross-link GCGO aerogels and improve their stability: the samples were introduced into an oven at $100{ }^{\circ} \mathrm{C}$ for $48 \mathrm{~h}$ under vacuum $(0.01 \mathrm{mbar})$.

Synthesis of Gelatin-Chitosan aerogels as control for the coating approach (CG-C). A $2 \% \mathrm{w} / \mathrm{w}$ Gel solution was prepared dissolving $8 \mathrm{~g}$ in $400 \mathrm{~mL}$ of Milli-Q at $45^{\circ} \mathrm{C}$ and a $2 \% \mathrm{w} / \mathrm{w}$ Chit solution was prepared dissolving $3.43 \mathrm{~g}$ in $171.42 \mathrm{~mL}$ of $1 \%$ acetic solution till its complete dissolution. Gel and Chit solution were blended at room temperature for $15 \mathrm{~min}$ in order to obtain a Gel:Chit ratio of $70: 30$ and a final blend concentration of $2 \% \mathrm{w} / \mathrm{w}$. 
179 The GC hydrogel was introduced into a specific home-made mould with a copper bottom and 180 plastic wall and, after gelation, was freeze-dried by setting a specific freeze-drying cycle: a freezing 181 ramp of $50{ }^{\circ} \mathrm{C} / \mathrm{h}$, until $-40{ }^{\circ} \mathrm{C}$ and a controlled heating ramp of $5{ }^{\circ} \mathrm{C} / \mathrm{h}$ from $-40{ }^{\circ} \mathrm{C}$ to $-10{ }^{\circ} \mathrm{C}$ and to $18215^{\circ} \mathrm{C}$ at $3^{\circ} \mathrm{C} / \mathrm{h}$. The customised mould and process were essential to obtain a perfect vertical growth 183 of ice crystals and thus an aligned structure in the dried aerogel. DHT treatment was carried out 184 after freeze-drying to cross-link GC aerogels and improve their stability. Samples were introduced 185 into an oven at $160{ }^{\circ} \mathrm{C}$ for $48 \mathrm{~h}$ under vacuum (0.01 mbar).

186 Synthesis of CGGO-C. A 2\% w/w Gel solution was prepared dissolving $8 \mathrm{~g}$ in $400 \mathrm{~mL}$ of Milli-Q 187 at $45{ }^{\circ} \mathrm{C}$ and a $2 \% \mathrm{w} / \mathrm{w}$ Chit solution was prepared dissolving $3.43 \mathrm{~g}$ in $171.42 \mathrm{~mL}$ of $1 \%$ acetic 188 solution till its complete dissolution. Gel and Chit solution were blended at room temperature for 15 189 min in order to obtain a Chit:Gel ratio of $30: 70$ and a final blend concentration of $2 \% \mathrm{w} / \mathrm{w}$.

190 The CG hydrogel was freeze-dried was introduced into a specific home-made mould with a copper 191 bottom and plastic wall and, after gelation, was freeze-dried by setting a specific freeze-drying cycle: a freezing ramp of $50{ }^{\circ} \mathrm{C} / \mathrm{h}$, until $-40{ }^{\circ} \mathrm{C}$ and a controlled heating ramp of $5{ }^{\circ} \mathrm{C} / \mathrm{h}$ from $-40{ }^{\circ} \mathrm{C}$ to $-10{ }^{\circ} \mathrm{C}$ and to $15^{\circ} \mathrm{C}$ at $3^{\circ} \mathrm{C} / \mathrm{h}$. The customised mould and process were essential to obtain a 194 perfect vertical growth of ice crystals and thus an aligned structure in the dried aerogel. DHT 195 treatment was carried out after freeze-drying to cross-link CG aerogels and improve their stability. 196 Aerogels were introduced into an oven at $160{ }^{\circ} \mathrm{C}$ for $48 \mathrm{~h}$ under vacuum $(0.01 \mathrm{mbar})$.

197 GO suspension was prepared dispersing $0.572 \mathrm{~g}$ in $228.5 \mathrm{~mL}$ of Milli-Q using a tip sonicator 198 (Sonics, Vibra cell, VCX500, max power 500W, ampl. $40 \%$ for $10 \mathrm{~min}$ ). The GO suspension was 199 dropped into GC aerogels in order to obtain a final GO:blend weight ratio of 5:95 and maintained at 200 room temperature for $15 \mathrm{~min}$. Dried aerogels was obtained through another freeze-drying with the 201 same cycle performed before (freezing ramp of $50{ }^{\circ} \mathrm{C} / \mathrm{h}$ until $-40{ }^{\circ} \mathrm{C}$ and with a controlled heating ramp of $5{ }^{\circ} \mathrm{C} / \mathrm{h}$ from $-40{ }^{\circ} \mathrm{C}$ to $-10{ }^{\circ} \mathrm{C}$ and to $15^{\circ} \mathrm{C}$ at $\left.3^{\circ} \mathrm{C} / \mathrm{h}\right)$. 
204 The scaffold morphology and the pore size were observed by environmental scanning electron 205 microscopy (ESEM) (Quanta 600 FEG, FEI Company, Hillsbrono, OR). The specimens were 206 mounted on aluminium stubs using carbon tape, and they were covered with a coating of Au using 207 coating units Polaron Sputter Coater E5100 (Polaron Equipment, Watford, Hertfordshire, U.K.). 208 The porosity was evaluated by two different methods: the density method and the water squeezing 209 method (details in Supporting Information, Table S1). The presence of GO coating onto aerogels 210 was observed with SEM (ZEISS LEO 1530 FEG, Germany), operated at $5 \mathrm{kV}$ and secondary 211 electrons were collected by means of an In-Lens detector.

\subsection{X-Ray Photoelectron spectroscopy (XPS)}

213 The aerogels were cut in $1 \mathrm{~mm}$ thin slice and fixed on conductive carbon tape for X-Ray

214 Photoelectron analysis. The XPS spectra were recorded with a Phoibos 100 hemispherical energy 215 analyser (Specs, Germany) using $\mathrm{Mg} \mathrm{K} \alpha$ radiation $(\hbar \omega=1253.6 \mathrm{eV}$; X-Ray power $=125 \mathrm{~W})$ in constant analyser energy (CAE) mode, with analyser pass energies of $10 \mathrm{eV}$ and overall resolution of $0.9 \mathrm{eV}$ on $\mathrm{Ag} 3 \mathrm{~d}$ peak. The base pressure in the analysis chamber during analysis was $2 \cdot 10^{-9}$ mbar. All spectra were calibrated to the C 1s binging energy $(285.0 \mathrm{eV})$. Spectra were fitted by using CasaXPS data analysis software (www.casaxps.com). The atomic \% were obtained from survey spectrum, while the shape of $\mathrm{C}$ 1s peak was acquired in order to identify the $\mathrm{C}-\mathrm{O}$ and $\mathrm{C}-\mathrm{N}$ present.

\subsection{Adsorption of ofloxacin and ciprofloxacin}

Kinetic experiments were performed in batch by dispersing the selected material $(50 \mathrm{mg})$ in $10 \mathrm{~mL}$ of solution of ofloxacin and ciprofloxacin mixture $(0.5 \mathrm{mg} / \mathrm{L}$ each $)$ and mixing with rotator stirred speed $32 \mathrm{rpm}$ in darkness and the solutions analyzed at selected intervals (1, 4 and $24 \mathrm{~h})$. For isotherm experiments of ofloxacin a stock solution at $500 \mathrm{mg} / \mathrm{L}$ in tap water was prepared. Adsorption experiments were performed by dispersing $50 \mathrm{mg}$ of the selected material in $10 \mathrm{ml}$ of ofloxacin solution (tap water) at $0.5,5,25,50,250,500 \mathrm{mg} / \mathrm{L}$, prepared by dilution of the stock solution and mixed (32 rpm) for $24 \mathrm{~h}$. 
230 For isotherm experiments of ciprofloxacin, a stock solution at $250 \mathrm{mg} / \mathrm{L}$ in tap water was prepared.

231 Adsorption experiments were performed by dispersing $50 \mathrm{mg}$ of the selected material in $10 \mathrm{ml}$ of 232 ciprofloxacin solution (tap water) at $0.5,5,25,50,250 \mathrm{mg} / \mathrm{L}$, prepared by dilution of the stock 233 solution and mixed (32 rpm) for $24 \mathrm{~h}$.

234 Antibiotics were detected by HPLC (Dyonex Ultimate 3000) system equipped with a diode array 235 detector. Automated injection volume was $0.2 \mathrm{~mL}$. LC-MS grade acetonitrile was purchased from 236 Sigma-Aldrich at the highest available purity and used without any further purification. Ultrapure water $\left(18.2 \mathrm{M} \Omega / \mathrm{cm}\right.$ at $25^{\circ} \mathrm{C}$, Millipore Milli-Q system) was used. The chromatographic separation was performed on a reverse phase Zorbax C8 column 4.6 x $150 \mathrm{~mm}, 5 \mu \mathrm{m}$, at flow rate of 1.0 $\mathrm{mL} / \mathrm{min}$ and detection performed, at maximum UV absorption of the selected analyte (details in Table S1-2 in SI). In all experiments the removal of analytes was determined by comparison with untreated solution.

\subsection{Adsorption of lead}

243 Kinetic adsorption of $\mathrm{Pb}$ was studied in batch tests by dispersing the selected material (about 40 $\mathrm{mg}$ ) in $40 \mathrm{ml}$ of $100 \mu \mathrm{g} / \mathrm{L} \mathrm{Pb}$ solution (Milli-Q water, $\mathrm{pH}$ 7). Solutions were mildly shaken onto orbital shaker (160 osc/min) and samples ( $2 \mathrm{ml}$ taken by syringe without filtering) were taken at selected interval (1, 3 and $24 \mathrm{~h})$.

Adsorption isotherms in batches were carried out to evaluate efficiency of different materials to remove $\mathrm{Pb}$. One sample, previously equilibrated in Milli-Q, was weighed (range 40-50 mg) and added to Milli-Q solutions (40 $\mathrm{ml}$ in Falcon) spiked at different levels of $\mathrm{Pb}(0-20 \mathrm{mg} / \mathrm{L})$ using $\mathrm{Pb}$ stock solution ( $1 \mathrm{~g} / \mathrm{L}$, Fluka). $\mathrm{pH}$ was initially adjusted to $\mathrm{pH} 6.5 \pm 0.5$. Solutions were mildly shaken onto orbital shaker (160 osc/min) for $24 \mathrm{~h} .2 \mathrm{ml}$ of samples were taken by syringe without 252 filtering.

253 All samples for adsorption studies (kinetic and isotherm) were run in duplicate, mean and standard deviation reported. $\mathrm{Pb}$ was measured by Atomic Absorption Spectrometer (AAS, AAnalyst800, Perkin Elmer) onto Ir-coated furnace. 
After last isotherm level, a release test of adsorbed $\mathrm{Pb}$ was performed to evaluate if strong chemiosorption was the mechanism involving $\mathrm{Pb}$ removal or it was more pore diffusion into nano-porous sponge structure. Each aerogel was put into $10 \mathrm{ml}$ Milli-Q (3 times, R1, R2 and R3 namely) and shaken at $240 \mathrm{osc} / \mathrm{min} . \mathrm{Pb}$ released was analyzed after 30 min contact time (R1 and then $\mathrm{R} 2)$ and after 48 hours (R3). A cumulative \% release value is given comparing mass release to adsorbed 261 amount.

\subsection{Adsorption models}

263 Adsorption process was described by three different models Freudlich, Langmuir and BET, usually 264 the most suitable to mimic pollutants equilibria with the adsorbent phase (Foo and Hameed, 2010; 265 Limousin et al., 2007). Freundlich empirical model considers adsorption sites at different energies 266 with stronger binding sites firstly occupied, while Langmuir model is based on experimental 267 evidences and it describes solute-adsorbent equilibrium by assuming a monolayer coverage with all 268 sites energetically equally probable. BET model is based on the assumption that exists a multilayer 269 coverage and represents an extension of Langmuir model. A detailed model and relative parameters 270 description are provided by Casentini et al., (2019). Briefly, we summarize hereafter used 271 equations:

275 where $\mathrm{q}_{\mathrm{e}}$ is the measured equilibrium adsorption capacity ( $\left.\mathrm{mg} / \mathrm{g}_{\mathrm{adsorb}}\right), \mathrm{C}_{\mathrm{e}}$ is the measured 276 equilibrium solute concentration $(\mathrm{mg} / \mathrm{L}), \mathrm{K}_{\mathrm{f}}$ is an indicator of the adsorption capacity $(\mathrm{L} / \mathrm{mg})$ and $2771 / \mathrm{n}$ is an indicator of adsorption intensity.

$$
q_{e}=\frac{q_{\max } b C_{e}}{1+b C_{e}}
$$


where $\mathrm{q}_{\mathrm{e}}$ is the measured equilibrium adsorption capacity $\left(\mathrm{mg} / \mathrm{g}_{\text {adsorbent }}\right), \mathrm{C}_{\mathrm{e}}$ the equilibrium solute 281 concentration $(\mathrm{mg} / \mathrm{L}), \mathrm{q}_{\max }$ corresponds to the maximum adsorption capacity of a monolayer stratum $282\left(\mathrm{mg}_{\mathrm{Pb}} / \mathrm{g}_{\mathrm{adsorbent}}\right)$ and $\mathrm{b}$ is Langmuir coefficient $(\mathrm{L} / \mathrm{mg})$.

BET model

$$
q_{e}=\frac{K_{b} C_{e} q_{\max }}{\left(C_{s}-C_{e}\right)\left[1+\left(K_{b}-1\right) \frac{C_{e}}{C_{s}}\right]}
$$

where $\mathrm{q}_{\mathrm{e}}$ is the measured equilibrium adsorption capacity $\left(\mathrm{mg} / \mathrm{g}_{\text {adsorbent }}\right), \mathrm{C}_{\mathrm{e}}$ is the measured equilibrium solute concentration $(\mathrm{mg} / \mathrm{L}), \mathrm{C}_{\mathrm{S}}$ is solute concentration saturating first layer $(\mathrm{mg} / \mathrm{L})$, $\mathrm{q}_{\max }$ is the maximum adsorption capacity of a monolayer stratum ( $\left.\mathrm{mg} / \mathrm{g}_{\text {adsorbent }}\right)$ corresponding to Langmuir model.

The goodness of fit was then evaluated by calculating the coefficient of determination $\left(\mathrm{R}^{2}\right)$ and the Root Mean Square Error (RMSE), as described in Casentini et al. (2019).

\subsection{Flow cytometry}

292 Samples were collected in 2-mL Eppendorf safe-lock tubes and analyzed soon after sampling. 293 Groundwater used for the test was collected from a nearby well. The natural groundwater non294 pathogenic microbial community characterization was estimated by the Flow Cytometer A50-micro 295 (Apogee Flow System, Hertfordshire, England) equipped with a solid-state laser set at $20 \mathrm{mV}$ and tuned to an excitation wavelength of 488 nm." Following previously published protocols 297 (Amalfitano et al., 2018), the volumetric absolute cell counting was carried out by staining with 298 either SYBR Green I (1:10000 final dilution; Molecular Probes, Eugene, OR, USA) or SYBR 299 Green I and Propidium Iodide (PI= $10 \mu \mathrm{g} / \mathrm{mL}$ final concentration) for $10 \mathrm{~min}$ in the dark at room 300 temperature. The light scattering signals (forward and side scatters), the green fluorescence (530/30 $301 \mathrm{~nm})$ and red fluorescence $(>610 \mathrm{~nm})$ were acquired for the single cell characterization. 302 Thresholding was carried out using the green channel. Samples were run at low flow rates to keep 303 the number of events below 1000 event $\mathrm{s}^{-1}$. The data were analyzed using the Apogee Histogram 304 Software (v89.0). The total cell counts were determined by signatures in a plot of the side scatter vs 
305 the green fluorescence. Live and dead cells were differentiated in a plot of green vs red 306 fluorescence. Viable cells showed higher green fluorescence signals than the membrane 307 compromised dead cells selectively marked in red by PI (Amalfitano et al., 2009).

\section{Results and Discussion}

\subsection{Synthesis and morphologies of CGGO aerogels}

311 Chitosan-Gelatin-GO aerogels (CGGO) and their control samples (CG) were prepared by a 312 blending-freeze drying based approach. Moreover, to obtain stable aerogels in wet condition a 313 physical cross-linking, dehydrothermal treatment (DHT), was carried out. Indeed, as previously 314 demonstrated, due to the temperature and vacuum condition of DHT process, covalent amidic bonds 315 between gelatin and chitosan are created upon DHT process, this increasing the chemical and 316 mechanical robustness of the final aerogel (Campodoni et al., 2019).

317 For the preparation of the GO embedded aerogel, CGGO-E, GO was introduced in the polymeric 318 hydrogel before gelation and freeze-drying. The dried composite CGGO-E, aerogel underwent DHT 319 treatment for further stabilization at $100{ }^{\circ} \mathrm{C}$ to prevent reduction of GO (Backes et al., 2020). The 320 control sample CG-E was prepared under the same experimental conditions.

321 On the other hand, for the preparation of GO coated aerogel CGGO-C, a GO suspension was 322 dropped on an already DHT stabilized aerogel. For both embedded and coated aerogels the ratio 323 GC:GO in the blend was about $2 \% \mathrm{w} / \mathrm{w}$ of GO. Details on the preparation conditions are reported in 324 the experimental section and in Fig. S1.

325 The macroscopic images of the aerogels and their morphologies at different magnification are 326 shown in Fig. 1 and Fig. S2. GO free aerogels showed a pale yellow colour while as expected, a 327 dark colour was observed after the addition of GO in both embedded and coated samples.

328 On the other hand, large tubular pores featured by aligned channels were observed for all samples 329 independently on the presence of GO, this being beneficial for water permeation. Density 330 experiments (see Table S1) were also carried out to estimate the porosity. Control samples CG-E 

revealed a porosity lower than the GO embedded ones (Fig. 1).
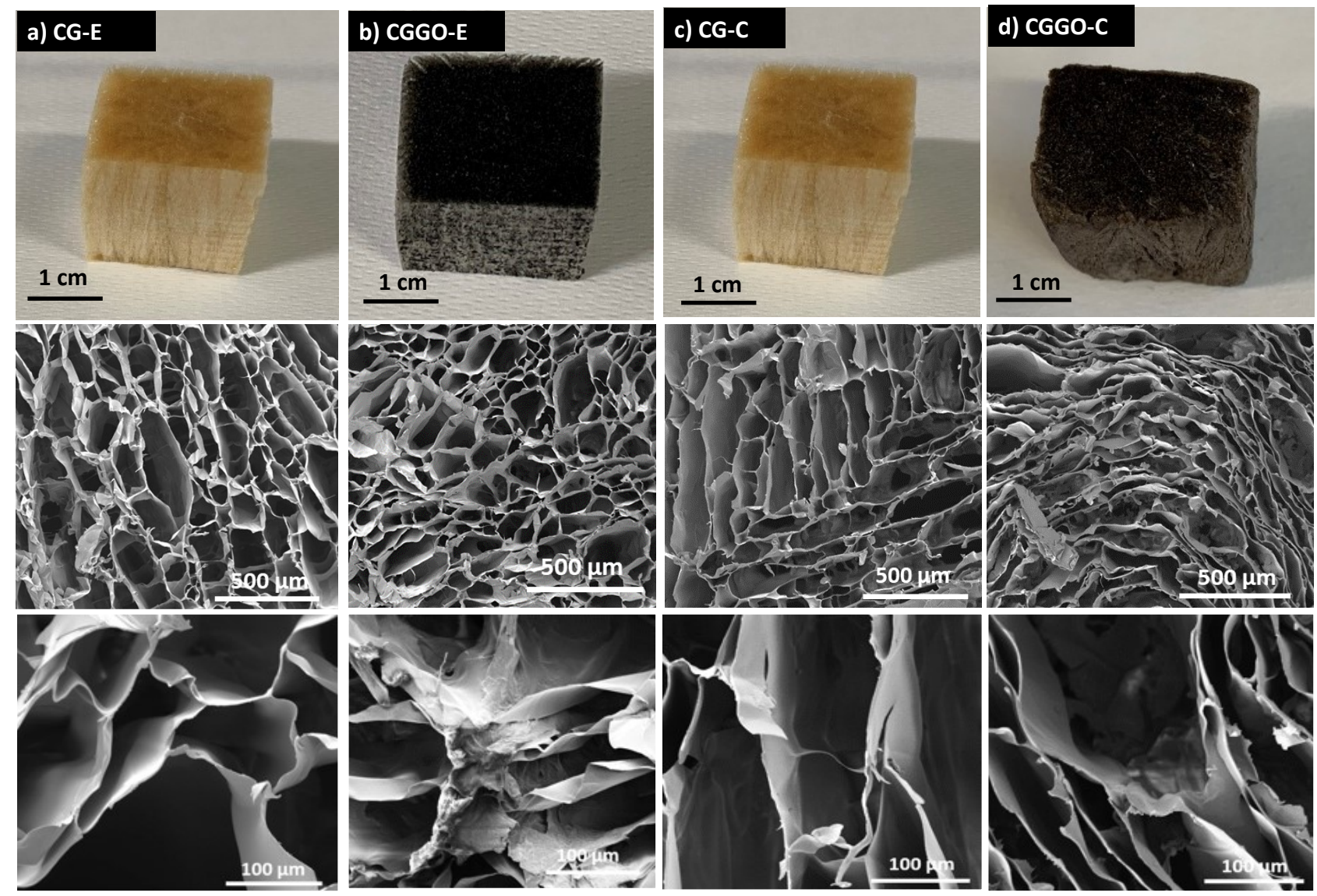

334 Fig. 1. ESEM images of cross-sections at different magnifications of polymeric (CG-E, CG-C) and

335 composite (CGGO-E, CGGO-C) aerogels. Aerogels up to $20 \mathrm{~cm}$ sized were prepared.

A GO continuous film with thickness in the order of magnitude of tens of $\mathrm{nm}$ was expected in CGGO-C aerogel (Fig. 2), similar to our previous coating of polysulfone hollow fibers (Kovtun et

339 al., 2019a). Wrinkle typically related to GO were clearly visible and not observed in CG-G control 340 samples, which showed a smooth surface. The GO coating was even more visible at high 341 magnification in proximity of few micrometre large crevice (Fig. 2 c,d), where the coating was 342 partially detached from surface. 


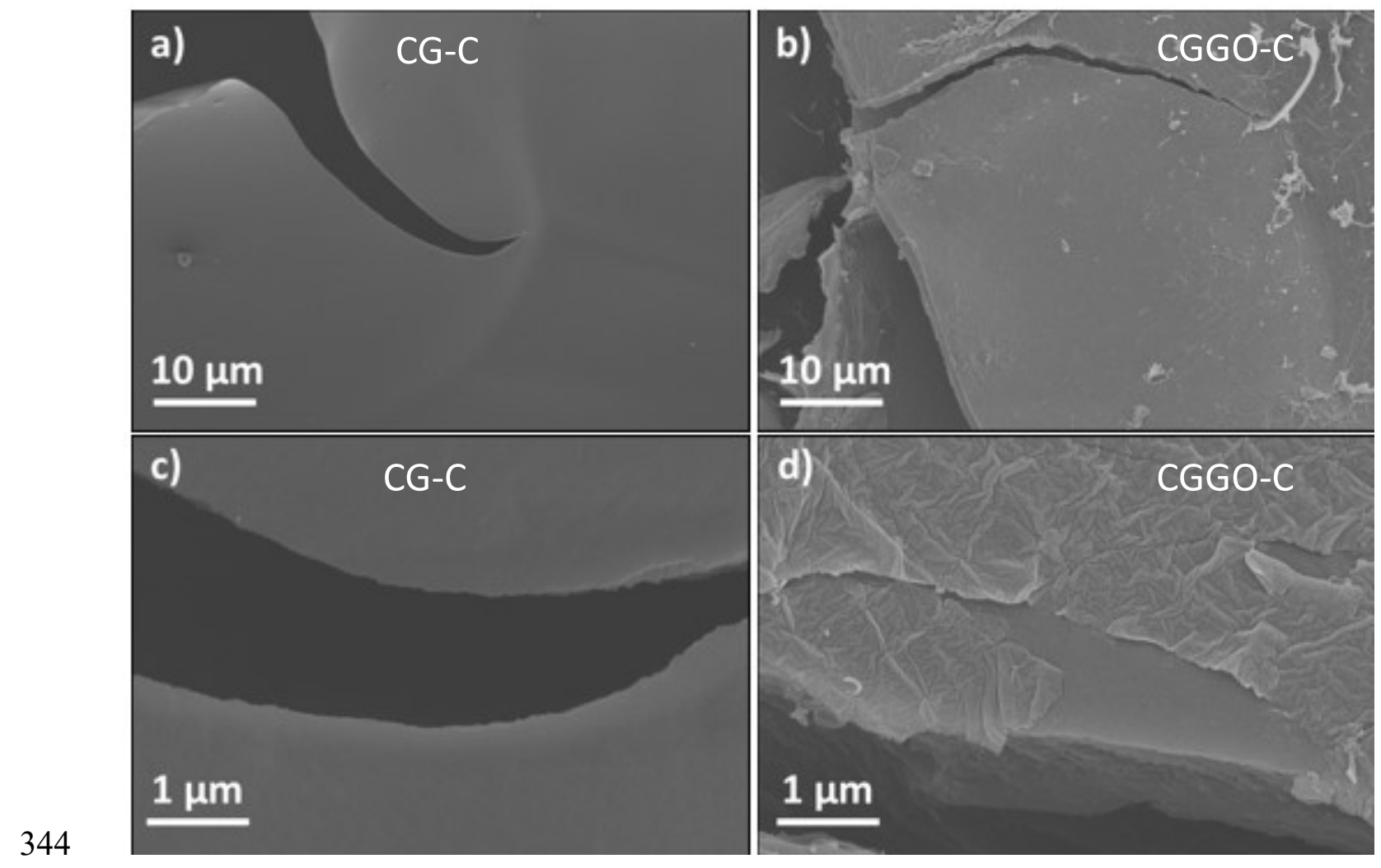

345 Fig. 2. FEG-SEM images of CG-C (a,c) and CGGO-C (b,d).

The stability of GO doped aerogels was tested by monitoring the GO release in water after $24 \mathrm{~h}$ of 348 static contact. GO release was evaluated by UV-Vis spectroscopy in comparison to GO standard 349 solutions. No evidence of GO was found in case of CGGO-E/C, hence we excluded any release at 350 least in the detection limit range of UV-Vis spectroscopy (about $2 \mathrm{mg} / \mathrm{L}$ ) (Kovtun et al., 2020; 351 Kovtun et al., 2019a) for both embedded and coated aerogels (Fig. S3).

\subsection{X-ray photoelectron spectroscopy (XPS)}

354 XPS experiments were performed to check if the fabrication process induced GO changes, i.e. 355 reduction to graphene. Survey spectra showed the signal form C 1s, N 1s and O 1s transitions (Fig. 356 3). The measured atomic \% were close to those reported by Maachou et al. (2013) for pristine 357 chitosan (C:O: $\mathrm{N}=63.6: 29.2: 7.3)$. The binding energy (B.E.) of $\mathrm{O}$ 1s and $\mathrm{N}$ 1s peaks were in 358 excellent agreement with literature, respectively $532.7 \pm 0.1$ and $399.5 \pm 0.1 \mathrm{eV}$ and the high359 resolution $\mathrm{C}$ 1s peak confirmed the chemical structure of chitosan (Maachou et al., 2013): one C-C 
360 group $(284.8 \mathrm{eV})$, one $\mathrm{O}-\mathrm{C}-\mathrm{O}$ group $(287.7 \mathrm{eV})$, while the three $\mathrm{C}-\mathrm{O}$ and the $\mathrm{C}-\mathrm{N}$ carbons present 361 the same B.E. $(286.2 \mathrm{eV})$. The measured C 1s signal (Fig. S4) was in good agreement with 362 literature, C-C peak is at $284.8 \pm 0.1 \mathrm{eV}, \mathrm{C}-\mathrm{O} / \mathrm{C}-\mathrm{N}$ at $286.4 \pm 0.1 \mathrm{eV}$ and $\mathrm{O}-\mathrm{C}-\mathrm{O}$ at $287.9 \pm 0.1 \mathrm{eV}$, the 363 relative abundances of carbon functional groups were close to pure chitosan. However, the amount 364 of C-C carbon is slightly higher respect to the theoretical value, probably due to residual from gel 365 and/or to the atmospheric contaminations (samples were stored in air).

366 The $\mathrm{C}$ 1s signal from CG-B, CGGO-B and CG-C featured the same shape and could be associated 367 to the chemical structure of chitosan, while the C 1s of CGGO-C showed a completely different 368 shape, not compatible with chitosan: the presence of aromatic and aliphatic C-C bonds at c.a. 285 $369 \mathrm{eV}$ and the peak at $286.7 \mathrm{eV}$ indicated that $\mathrm{GO}$ was present in large amount on surface. 370 Consequently, the $\mathrm{C}$ 1s peak was fitted by using the model proposed for GO (Kovtun et al., 2019b) 371 i.e. aromatic carbon $\left(\mathrm{C}=\mathrm{C} \mathrm{sp}{ }^{2}, 284.4 \mathrm{eV}\right)$, aliphatic carbon $\left(\mathrm{C}-\mathrm{C} \mathrm{sp}{ }^{3}, 285.0 \mathrm{eV}\right)$, hydroxyl $(\mathrm{C}-\mathrm{OH}$, $372285.7 \mathrm{eV})$, epoxy $(\mathrm{C}-\mathrm{O}-\mathrm{C}, 286.7 \mathrm{eV})$, carbonyl $(\mathrm{C}=\mathrm{O}, 288.0 \mathrm{eV})$, carboxyl $(\mathrm{O}-\mathrm{C}=\mathrm{O}, 289.1 \mathrm{eV})$ and 373 aromatic carbons near vacancies (C-C* $\left.\mathrm{sp}^{2}, 283.5\right)$ (Larciprete et al., 2012). Moreover, the amount 374 of $\mathrm{N} 1 \mathrm{~s}$ was extremely low respect to the other aerogels (1.7\% compared with $10 \%)$, this 375 confirming the high coverage of GO on CGGO-C surface. 

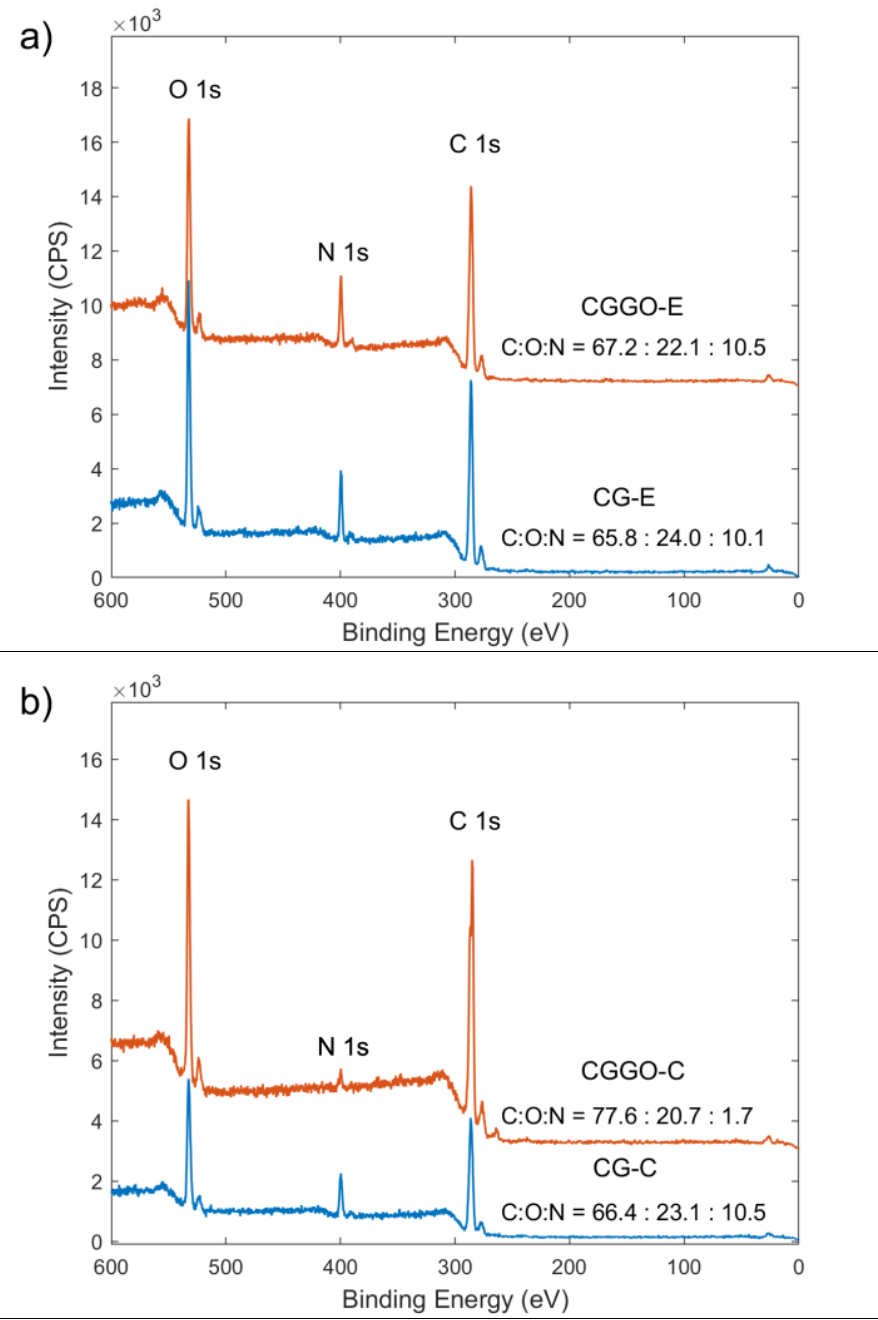

Fig. 3. Survey XPS spectra of a) CG-E and CGGO-E; b) CG-C and CGGO-C. The composition

379 obtained from each spectrum are reported as atomic \%.

\subsection{Adsorption tests embedded vs coated aerogels}

383 The adsorption kinetic of ofloxacin and ciprofloxacin (Fig. S5) of GO-doped materials and of GO-

384 free control samples was tested over time (1-4-24 h) by dipping an aerogel sample in a solution of 385 the two compounds at $0.5 \mathrm{mg} / \mathrm{L}$ in tap water. Negligible adsorption was found for chitosan-gelatin 386 controls even after $24 \mathrm{~h}$ treatment (figure 4 and fig. S5 for ciprofloxacin). On the other hand, GO embedded aerogels GCGO-E showed removals of $45 \%$ and $70 \%$ for ofloxacin and ciprofloxacin 
389 removal around $70 \%$ for both compounds already after $1 \mathrm{~h}$ treatment.

a)

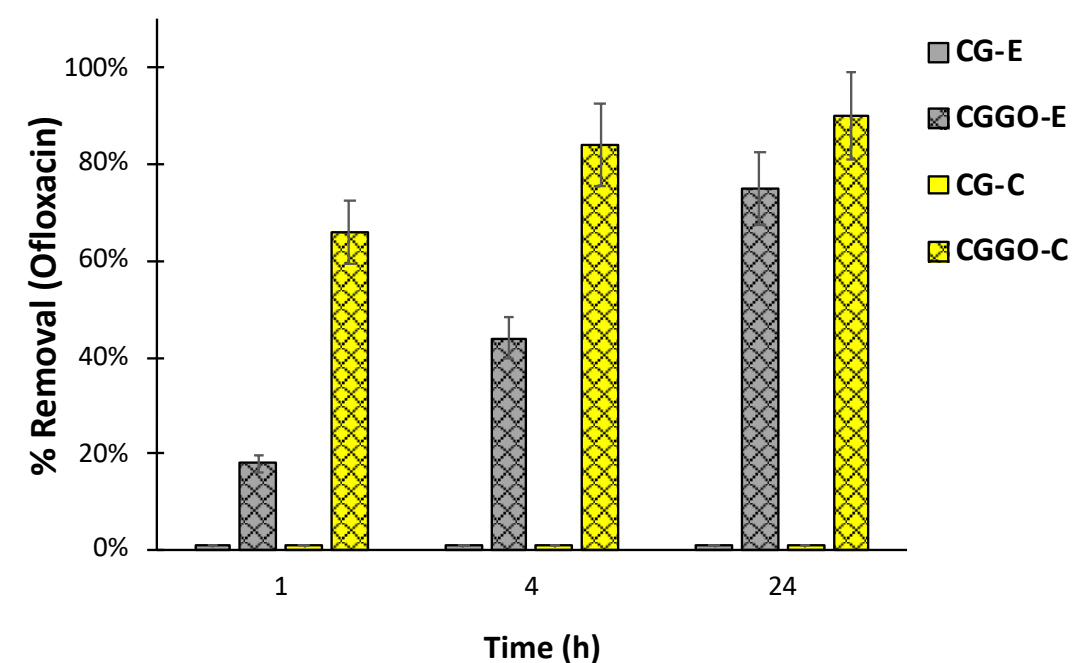

b)

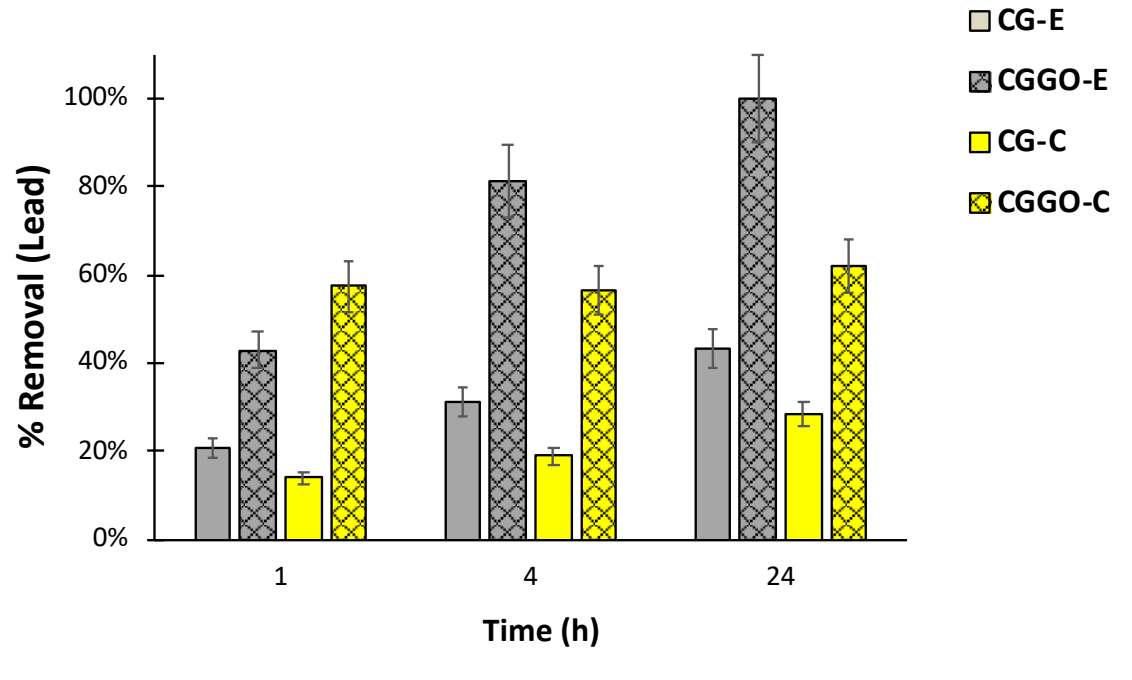

392 Fig. 4. Kinetics of removal of ofloxacin (a) and $\mathrm{Pb}$ (b) by the different samples. The initial 393 concentration of $\mathrm{Pb}$ and ofloxacin was $100 \mu \mathrm{g} / \mathrm{L}$ and $500 \mu \mathrm{g} / \mathrm{L}$, respectively. Kinetic for 394 ciprofloxacin adsorption is shown in Fig. S5.

396 For both systems the removal of ofloxacin and ciprofloxacin increased with time indeed values up 397 to $80-90 \%$ were found after $24 \mathrm{~h}$ (see also Fig. S5 for ciprofloxacin), this suggesting that the 398 diffusion of both organic molecules into the aerogel was similar and not very fast. 
$399 \mathrm{~Pb}$ removal efficiency was about $60 \%$ and quite stable over time for CGGO-C, while it ranged from $400 \quad 43 \%(1 \mathrm{~h})$ to $100 \%(24 \mathrm{~h})$ for CGGO-E.

401 We conclude that for $\mathrm{Pb}^{+2}$ adsorption contact time was not a limiting factor for coated material 402 (CGGO-C), where all adsorption sites are easy reachable on the surface while diffusion into 403 materials becoming very important in embedded material (CGGO-E) where increasing the contact 404 time adsorption increases, indicating that in this case active sites are less promptly available. In 405 control samples (aerogel without GO) negatively charged surface of chitosan also provide good 406 electrostatic attraction for positive $\mathrm{Pb}$ (Mishra et al., 2013; Wan et al., 2010) and the removal at an 407 initial concentration of $100 \mu \mathrm{g} / \mathrm{L}$ was $20.8-43.1 \%$ in CG-E and $13.9-20.5 \%$ in CG-C. Wan et al. 408 (2010) showed that at $\mathrm{pH}$ above 4 metals removal by chitosan increased and reached a plateau 409 indicating that at circumneutral $\mathrm{pH}$, as in our case $(\mathrm{pH} 7)$ the amino group was deprotonated. At this 410 condition the chelation mechanism outranked the adsorption mechanism where more metal ions 411 chelate with chitosan.

412 Adsorption isotherms experiments were performed to establish the maximum adsorption capacity 413 (see Section 2.4 and 2.5 and results in Table S2 and S3). Different isotherm models were taken into 414 accounts, however as shown by Fig. 5 the adsorption is well described by BET model, indicating a 415 multilayer adsorption, and the difference in performance between bulk (CGGO-E) ad coating 416 (CGGO-C) were negligible with $1^{\text {st }}$ layer maximum adsorption capacity in the range between 4 and $4178 \mathrm{mg} / \mathrm{g}$ in samples with GO (CGGO-E and CGGO-C). In the case of embedded material the $1^{\text {st }}$ 418 layer maximum adsorption $\mathrm{q}_{\max }=4.6 \mathrm{mg} / \mathrm{g}$ (ofloxacin) is in agreement with the maximum capacity 419 of polysulfone-GO membranes doped with 5\% w/w of GO and obtained by phase inversion 420 (Zambianchi et al., 2017) (i.e. $\mathrm{q}_{\max } 4 \mathrm{mg} / \mathrm{g}$ ) and it is similar to the maximum capacity of coated 421 sample CGGO-C (8.3 mg/g). 

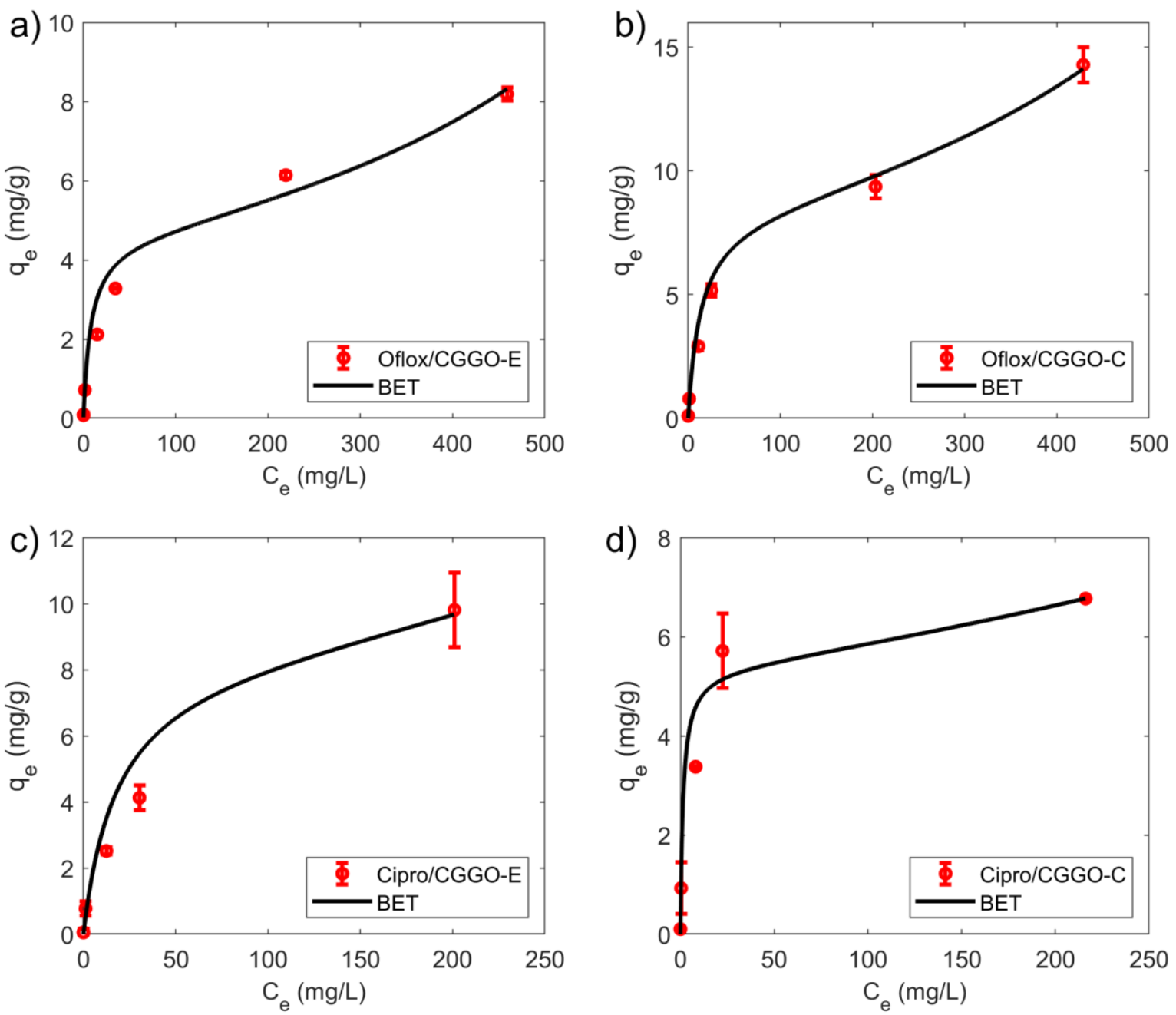

424 Fig. 5. Adsorption isoterms of Ofloxacin (a,b) and Ciprofloxacin (c,d) of CGGO-E (a,c) and 425 CGGO-C (b,d) samples.

427 Similarly to organic adsorptions tests, negligible removal was found for GO free samples at these 428 higher concentration. Neverthless, in the case of $\mathrm{Pb}$ removal, higher performances were estimated 429 for embedded sample CGGO-E respect to coated one CGGO-C.

430 Indeed, sample CGGO-E showed highest adsorption efficiency with a BET type behavior reaching 431 a max adsorption monolayer capacity of $11.1 \mathrm{mg} / \mathrm{g}$ while in its control without $\mathrm{GO} \mathrm{q}_{\max }$ was only $4320.7 \mathrm{mg} / \mathrm{g}$ according to Langmuir best fit (Fig. 6). Also, in the sample CGGO-C higher adsorption 433 was observed compared to its control, with monolayer max adsorption capacity $1.5 \mathrm{mg} / \mathrm{g}$ and 0.5 $434 \mathrm{mg} / \mathrm{g}$ for CGGO-C and CG-C, respectively (see Table S2 for model parameters and selection). 

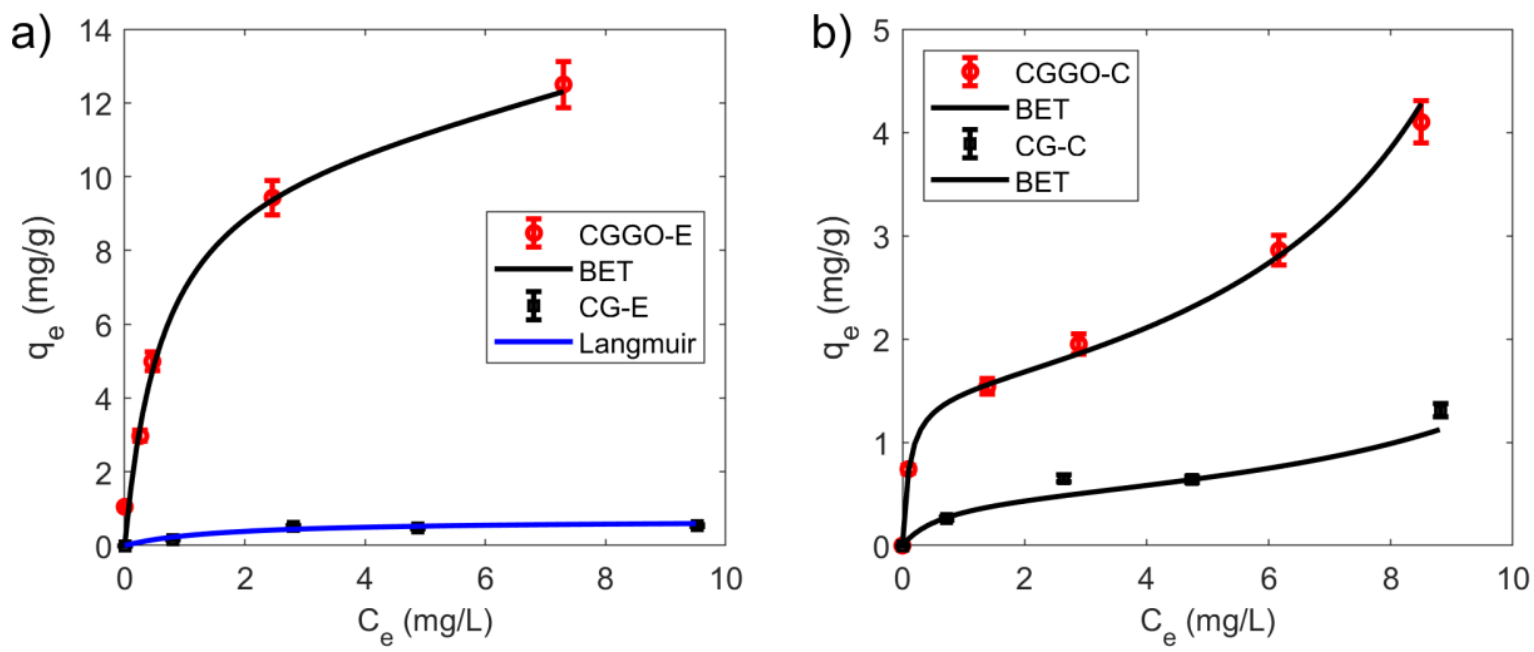

437 Fig. 6. $\mathrm{Pb}$ adsorption onto a) GO embedded aerogel and its control and b) GO coated aerogels and 438 its control. Data are reported as mean values and relative standard deviation. Best fitting prediction 439 model line are reported: BET model and Langmuir Model.

441 Table 1. Monolayer maximum adsorption capacity $\left(\mathrm{q}_{\max }\right.$ in $\left.\mathrm{mg} / \mathrm{g}\right)$ of ofloxacin, ciprofloxacin and $442 \mathrm{~Pb}$ on all samples. Values from BET adsorption model, except *Langmuir adsorption.
CG-E
CGGO-E
CG-C
CGGO-C

\begin{tabular}{lllll}
\hline Ciprofloxacin & $<0.1$ & $8.4 \pm 0.8$ & $<0.1$ & $5.3 \pm 0.5$ \\
Ofloxacin & $<0.1$ & $4.6 \pm 0.5$ & $<0.1$ & $8.3 \pm 0.8$ \\
Pb & $0.7 \pm 0.1^{*}$ & $11.1 \pm 0.3$ & $0.5 \pm 0.1$ & $1.5 \pm 0.1$
\end{tabular}

444 No release of organics was found, while release of the adsorbed $\mathrm{Pb}$ was about $7.2 \%$ by CGGO-E 445 and $34.8 \%$ by CGGO-C sponge. Therefore, adsorbed $\mathrm{Pb}$ is not only higher in embedded aerogels 446 but also more stable. The better performance of embedded aerogels can be likely ascribed to the 447 instauration of stronger monolayer adsorption bonds due to major availability of graphene 448 nanosheets at prolonged contact time while weaker multilayer adsorption at higher initial 
concentrations (up to $20 \mathrm{mg} / \mathrm{L}$ ) for coated aerogels is due to electrostatic repulsions on GO coating 450 surface, as confirmed by BET best fit.

451 Collectively, embedded systems showed slightly better removal capacity than coated one with 452 respect to the adsorption of both organics and $\mathrm{Pb}$, but adsorption was slower for $\mathrm{Pb}$. No adsorption 453 was observed for control systems CG-E/C in the case of ofloxacin and ciprofloxacin, hence their 454 removal can be totally ascribed to GO. On the contrary, $\mathrm{Pb}$ adsorption was also observed not coated 455 aerogels due electrostatic attraction and amino group chelation of chitosan, nevertheless GO coating raised significantly their removal efficiency.

\subsection{Microbial removal efficiency and viability assessment}

Flow cytometry was used as a rapid tool to assess the removal of the total microbial cells by 460 filtering waters through the aerogels (i.e. inlet vs outlet waters). Moreover, the microbial viability 461 was evaluated considering the increase of membrane-damaged cells in comparison to the control treatment. The performances of the new materials were evaluated by flow cytometry considering the changes in total cell counts (TCC) and membrane integrity (\% of dead cells over the total)

464 between the source and the filtered waters. The microbial water quality assessment of 465 nonpathogenic microorganisms through flow cytometry can be applied to determine the 466 effectiveness of water filtration treatments, also facilitating the optimization of reclamation 467 procedures in experimental and pilot studies and the upscaling to full-scale plants (Safford et al., 468 2019; Vergine et al., 2020).

469 In this study, TCC increased only slightly over time in comparison to the control sample with no 470 treatment, but without significant differences between treatments at $24 \mathrm{~h}$ of incubation. The CG 471 aerogels were likely to provide substrates suitable for microbial growth. However, potential 472 antimicrobial effects were clearly visible already at $1 \mathrm{~h}$ in CGGO-C, with an increase of one order of 473 magnitude of membrane-compromised cells in comparison to the control. Interestingly at $24 \mathrm{~h}$, a net 474 increase of dead cells was observed in all treatments (Fig. 7). The major antimicrobial effect 
475 observed at CGGO-C suggested that homogeneous GO coating on the sponge surface was more 476 effective in damaging cell membranes at the microbial community level than the GO-embedded 477 within the sponges. Our findings are in line with previous observations reported by testing pure 478 microbial cultures (Liu et al., 2018).

479
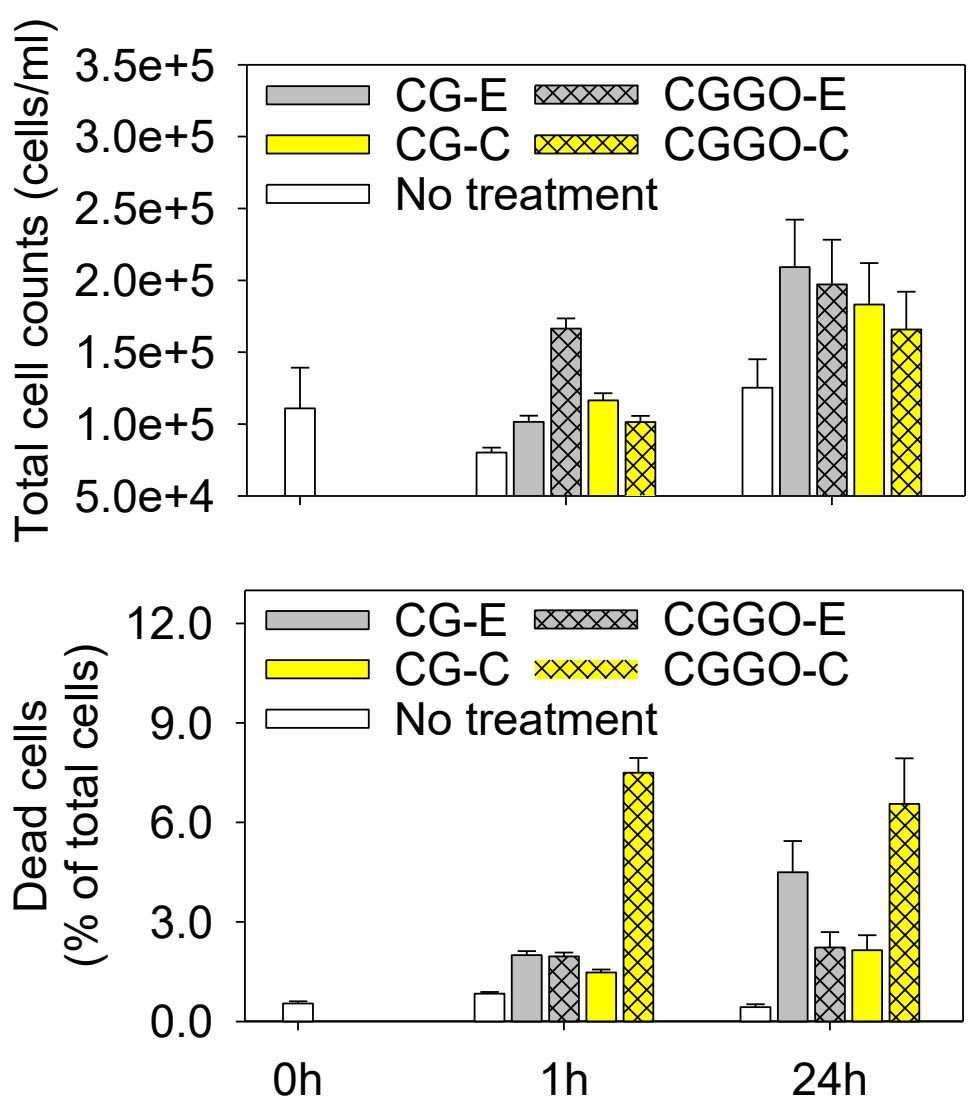

481 Fig. 7. Flow cytometric characterization of the water microbial community upon filtration through 482 CG and CGGO aerogels. The total cell counts, and the percentage of dead cells were assessed after $4831 \mathrm{~h}$ and $24 \mathrm{~h}$ from filtration. "No treatment" refers to water sample with no sponge.

\section{Conclusions}

In summary, we reported the fabrication of novel eco-sustainable aerogels made by chitosangelatin, CG, and GO and their characterization as adsorbent for water purification. We compared two different composites polymer-GO $(2 \% \mathrm{w} / \mathrm{w})$ consisting of i) bulk aerogels with $\mathrm{GO}$ embedded 
in the porous matrix and ii) aerogel coated with a GO layer. Adsorption tests performed on selected

491 fluoroquinolonic antibiotics and $\mathrm{Pb}$ contaminants showed faster adsorption for $\mathrm{GO}$ coated samples, especially for $\mathrm{Pb}$ ions. Similar maximum adsorption capacity between GO embedded and GO coated materials was observed with respect to fluoroquinolonic antibiotics. On the contrary, in the case of $\mathrm{Pb}$ the adsorption efficiency was significantly higher (one order of magnitude) and stronger in embedded samples where monolayer adsorption capacity was described by Langmuir model.

496 Collectively these results show that both GO embedding and coating are valuable strategies to exploit GO sorption capability through hydrophobic (GO-organics) or electrostatic (GO-Pb) interactions. For antibiotics removal, the amount of GO seems the key factor to maximize the removal efficacy while for $\mathrm{Pb}$ removal embedding approach seems to work better likely due to 500 instauration of stronger monolayer bonds onto available sites respect to coated samples.

501 In both cases, the comparison with GO free controls demonstrate that adsorption of ofloxacin, 502 ciprofloxacin and $\mathrm{Pb}$ can be totally ascribed to GO. Antimicrobial effects were visible already after

$5031 \mathrm{~h}$ of incubation, with an increase of one order of magnitude of membrane-compromised cells for 504 CGGO-C in comparison to the control, this being of relevance for possible implementation in filters 505 for drinking water.

506 In this work a limited amount of $\mathrm{GO}(2 \% \mathrm{w} / \mathrm{w})$ was used for the preparation the targeted 507 coated/embedded structures, but the fabrication procedure developed is compatible with higher GO 508 amounts. This would enhance the removal efficiency up to the maximum capacity allowed by GO, 509 making CGGO aerogels valuable candidates for the realization of truly multifunctional filters for 510 drinking water. Work in this direction is currently under way.

\section{Acknowledgments}

513 The research leading to these results has received funding from the European Union's Horizon 2020 
514 research and innovation programme under GrapheneCore2 785219 - Graphene Flagship, POR-

515 FERS 2014-2020 DGR 986/2018 MEDFIL (B54I19000030005) and Italian-PRIN 2017 NANO-

516 CARBOCAT (B54I19002770001) and FLAGERA JTC 2019 (825207)-GO-FOR-WATER.

518 References and Notes

$519{ }^{\ddagger}$ These authors contributed equally to this work.

521 Amalfitano, S., Fazi, S., Ejarque, E., Freixa, A., Romaní, A. M., Butturini, A., 2018. Deconvolution 522 model to resolve cytometric microbial community patterns in flowing waters. Cytometry Part A, 523 93(2), 194-200.

Amalfitano, S., Fazi, S., Puddu, A. 2009. Flow cytometric analysis of benthic prokaryotes attached to sediment particles. Journal of microbiological methods, 79(2), 246-249.

Baig, N., Sajid, I.M., Saleh, T.A., 2019. Graphene-based adsorbents for the removal of toxic organic pollutants: A review. J. Environ. Manage. 244, 370-382.

531 Barrios, E., Fox, D., Sip, Y. Y. L., Catarata, R. Calderon, J. E., Azim, N., Afrin S., Zhang Z., Zhai, 532 L., 2019. Nanomaterials in Advanced, High-Performance Aerogel Composites: A Review. 533 Polymers, 11, 726.

535 Backes, C., Abdelkader, A. M. Concepcion, A.et al., 2020. Production and processing of graphene 536 and related materials. 2D Materials, 7, 2, Article Number: 022001. 
538 Campodoni, E., Heggset, E. B., Rashad, A., Ramírez-Rodríguez, G. B., Mustafa, K., Syverud, K., 539 Tampieri, A., Sandri, M., 2019. Polymeric 3D scaffolds for tissue regeneration: Evaluation of 540 biopolymer nanocomposite reinforced with cellulose nanofibrils. Mater. Sci. Eng. C, 94, 867-878.

542 Casentini, B., Gallo, M.; Baldi, F., 2019. Arsenate and arsenite removal from contaminated water 543 by iron oxides nanoparticles formed inside a bacterial exopolysaccharide. J. Environ. Chem. Eng. 7, 544102908.

546 Ersan, G., Apul, O.G., Perreault, F., Karanfil, T., 2017. Adsorption of organic contaminants by 547 graphene nanosheets: a review. Water Res. 126, 385-398.

EU Watch List: https://ec.europa.eu/jrc/en/publication/review-1st-watch-list-under-water$\underline{\text { framework-directive-and-recommendations-2nd-watch-list }}$

Foo, K.Y., Hameed, B.H., 2010. Insights into Modeling of Adsorption Isotherm Systems. Chem.

Eng. J. 2010, 156, 2-10.

555 Good, K.D., Bergman, L. E., Klara, S.S., Leitch, M. E., Van Briesen, J.M., 2016. Implications of 556 Engineered Nanomaterials in Drinking Water Sources Journal of American Water Works Association- AWWA 108, 1, E1-E17.

559 Hartmann, J., Van der Aa, M., Wuijtsa, S., Roda Husmana, A.M., Van der Hoek, J.P., 2018. Risk 560 governance of potential emerging risks to drinking water quality: Analysing current practice. 561 Environ Sci Policy. 84, 97-104. 
563 Hosseinnejad, M., Jafari, S. M., 2016. Evaluation of different factors affecting antimicrobial 564 properties of chitosan. International journal of biological macromolecules, $85,467-475$.

566 Ji, K., Han, A., Hirata, A., Fujita, T., Shen, Y., Ning, S., Liu, P., Kashani, H., Tian, Y., Ito, Y., 567 Fujita, J.I., Oyama, Y., 2019. Lithium intercalation into bilayer graphene. Nat. Commun. 10, 275.

Joseph, L., Jun, B.M., Flora, J. R.V., Park, C.M., Yoon, Y., 2017. Removal of heavy metals from water sources in the developing world using low-cost materials: A review. Chemosphere. 229, 142159.

Kovtun, A., Zambianchi, M., Bettini, C., Liscio, A., Gazzano, M., Corticelli, F., Treossi, E., M. L.

Navacchia, Palermo, V., Melucci, M., 2019a. Graphene oxide-polysulfone filters for tap water purification, obtained by fast microwave oven Treatment. Nanoscale, 11, 22780-22787

Kovtun, A., Bianchi, A., Zambianchi, M., Bettini, C., Corticelli, F., Ruani, G., Bocchi, L., Stante,

F., Gazzano, M., Marforio, T. D., Calvaresi, M., Minelli, M., Navacchia, M. L., Palermo, V. Melucci, M., 2020. Core-shell graphene oxide-polymer hollow fibers as water filters with enhanced performance and selectivity, Faraday Discussions, DOI: 10.1039/C9FD00117D.

Kovtun, A., Jones, D., Dell'Elce, S., Treossi, E., Liscio, A., Palermo, V., 2019b. Accurate chemical analysis of graphene-based materials using X-ray photoelectron spectroscopy. Carbon 143, 268275.

Larciprete, R., Locovig, P., Gardonio, S., Baraldi, A., Lizzit, S., 2012. Dual Path Mechanism in the Thermal Reduction of Graphene Oxide. J. Phys. Chem. C, 116, 9900-9908. 
Krishnakumar, G. S., Gostynska, N., Dapporto, M., Campodoni, E., Montesi, M., Panseri, S., 589 Tampieri, A., Kon, E., Marcacci, M., Sprio, S., Sandri, M. 2018. Evaluation of different 590 crosslinking agents on hybrid biomimeticcollagen-hydroxyapatite composites for regenerative 591 medicin. Int. J. Biol. Macromol. 106, 739-748.

Lapworth, D.J., Baran, N., Stuarta, M.E., Warda, R.S., 2012. Emerging organic contaminants in 594 groundwater: A review of sources, fate and occurrence. Environ. Pollut. 163, 287-303.

Levallois, P., Barn, P., Valcke, M., Gauvin, D., Kosatsky, T., 2018. Public Health Consequences of Lead in Drinking Water. Curr. Environ. Health Rep. 5, 255-262.

Limousin, G., J.-P. Gaudet, J.-P., Charlet, L., Szenknect, S., Barthe`s, V., Krimissa, M.,2007. 600 Sorption isotherms: A review on physical bases, modeling and measurement. Appl. Geochem. $6012007,22,249-275$.

Liu, Y., Wen, J., Gao, Y., Li, T., Wang, H., Yan, H., Niu, B., Guo, R., 2018. Antibacterial graphene oxide coatings on polymer substrate. Applied Surface Science 436, 624-630.

605

606

Madadrang, C. J., Kim, H. Y., Gao, G., Wang, N., Zhu, J., Feng, H., Gorring, M., Marc L. Kasner, 607 M. L., Hou, S. 2012, Adsorption Behavior of EDTA-Graphene Oxide for Pb (II) Removal. ACS 608 Appl. Mater. Interfaces, 4, 1186-1193.

Maachou, H., Genet, M. J., Aliouche, D., Dupont-Gillain C. C., Rouxhet P. G., 2013.

611 XPS analysis of chitosan-hydroxyapatite biomaterials: from elements to compounds. Surf. Interface 612 Anal. 45, 1088-1097. 
614 Melucci, M., Durso, M., Zambianchi, M., Treossi, E., Xia, Z.-Y., Manet, I., Giambastiani, G., 615 Ortolani, L., Morandi, V., De Angelis, F., Palermo, V., 2012. Graphene-organic hybrids as 616 processable, tunable platforms for $\mathrm{pH}$-dependent photoemission, obtained by a new modular 617 approach. J. Mater. Chem., 22, 18237-18243.

619 Mishra, P. C., Islam M., Patel, R. K., 2013. Removal of Lead (II) by Chitosan from Aqueous 620 Medium. Separation Science and Technology,48:8,1234-1242.

Mukherjee1, S., Ren, Z., Singh, G., 2018. Beyond Graphene Anode Materials for Emerging Metal Ion Batteries and Supercapacitors. Nano-Micro lett. 10, 70.

Nappier, S. P., Soller, J. A., \& Eftim, S. E., 2018. Potable water reuse: what are the microbiological risks?. Current environmental health reports, 5(2), 283-292.

Patrolecco, L., Rauseo, J., Ademollo, N., Grenni, P., Cardoni, M., Levantesi, C., Luprano, M. L.,

Barra Caracciolo, A., 2018. Persistence of the antibiotic sulfamethoxazole in river water alone or in the co-presence of ciprofloxacin. Sci. Total Environ. 640-641, 1438-1446.

Peng, W., Li, H., Liu, Y., Song, S., 2017. A review on heavy metal ions adsorption from water by graphene oxide and its composites. J. Mol. Liq. 230, 496-504.

Pharmaceuticals in Drinking Water WHO/HSE/WSH/11.05 [Online] 2011. 
641 Recast of the EU drinking water directive: https://ec.europa.eu/info/law/better-regulation/haveyour-say/initiatives/1563-Revision-of-the-Drinking-Water-Directive-RECAST-2017-

Riva, F., Castiglioni, S., Fattorea, E., Manenti, A., Davolia, E., Zuccato, E., 2018. Monitoring Hyg. Environ. Health. 221, 3, 451-457.

Science \& Health, 7, 34-44.

Safford, H. R., Bischel, H. N., 2019. Flow cytometry applications in water treatment, distribution, and reuse: A review. Water Research,151, 110-133. contribution of water to antimicrobial resistance. JRC 114775.

Shankar, K. G., Gostynska, N., Montesi, M., Panseri, S., Sprio, S., Kon, E., Marcacci, M.,

Scaffolds for Tissue Engineering Application: A Comparative Analysis. Int. J. Biol. Macromol. 95, $661 \quad 1199-1209$.

663 Simeonidis, K., Mourdikoudis, S., Kaprara, E., Mitrakas, M., Polavarapu, L., 2016. Inorganic 664 engineered nanoparticles in drinking water treatment: a critical review. Environ. Sci.: Water Res. 665 Technol. 2, 43-70. 
667 Sweetman, M.J., May, S., Mebberson, N., Pendleton, P., Vasilev, K., Plush, S.E., Hayball, J.D., 668 2017. Activated carbon, carbon nanotubes and graphene: materials and composites for advanced 669 water purification. C. 3, 18.

671 Tabrizi, N. S., Zamani, S., 2016. Removal of $\mathrm{Pb}(\mathrm{II})$ from aqueous solutions by graphene oxide 672 aerogels. Water Sci Technol (1): 74, 256-265.

674 Troester, M., Brauch. H-J., Hofmann, T., 2016. Vulnerability of drinking water supplies to 675 engineered nanoparticles, Water Research 96, 255-279.

Vergine, P., Amalfitano, S., Salerno, C., Berardi, G., Pollice, A., 2020. Reuse of ultrafiltered 678 effluents for crop irrigation: On-site flow cytometry unveiled microbial removal patterns across a full-scale tertiary treatment. Science of The Total Environment, 718, 137298,

Wan, M.W., Kan, C.C., Rogel, B.D., Dalida, M.L.P., 2010. Adsorption of copper (II) and lead (II) 682 ions from aqueous solution on chitosan-coated sand. Carbohydrate Polymers, 80, 891-899.

684 Wan, S., He, F., Wu, J., Wan, W., Gu, Y., Gao, B., 2016. Rapid and highly selective removal of 685 lead from water using graphene oxide-hydrated manganese oxide nanocomposites. J. Hazard. 686 Mater. 314, 32-40.

688 Wang, J., Chen, B., 2015. Adsorption and coadsorption of organic pollutants and a heavy metal by 689 graphene oxide and reduced graphene materials. Chem. Eng. J. 281, 379-388. 
691 Westerhoff, P., Atkinson, A., Fortner, J., Wong, M. S., Zimmerman, J., Gardea-Torresdey, Ranville 692 J.J., Herckes, P., 2018. Low risk posed by engineered and incidental nanoparticles in drinking 693 water. Nature Nanotech. 13, 661-666.

694

695 Xu, J., Dou, Y., Wei, Z., Ma, J., Deng, Y., Li, Y., Liu, H., Dou, S., 2017. Recent Progress in 696 Graphite Intercalation Compounds for Rechargeable Metal (Li, Na, K, Al)-Ion Batteries. Adv. Sci. $697 \quad 4,1700146-1700146$.

698

699 Xu, J., Cao, Z., Zhang, Y., Yuan, Z., Lou, Z., Xu, X., Wang, X., 2018. A review of functionalized 700 carbon nanotubes and graphene for heavy metal adsorption from water: Preparation, application, 701 and mechanism, Chemosphere 195, 351-364.

703 Yang, R., Li, H., Huang, M., Yang, H., Li, A., 2016. A review on chitosan-based flocculants and 704 their applications in water treatment. Water Research, 95, 59-89.

706 Yousefi, N., Lu, X., Elimelech, M., Tufenkji, N., 2019. Environmental performance of graphene707 based 3D macrostructures. Nature Nanotechn. 14, 107-119.

709 Zambianchi, M., Durso, M., Liscio, A., Treossi, E., Bettini, C., Capobianco, M. L., Aluigi, A., 710 Kovtun, A., Ruani, G., Corticelli, F., Brucale, M., Palermo, V., Navacchia, M. L., Melucci, M., 7112017.

712 Graphene oxide doped polysulfone membrane adsorbers for the removal of organic contaminants 713 from water. Chemical Engineering Journal 326, 130-140. 
715 Zhang, Y. Q., Zhang, M., Jiang, H. Y., Shi, J. L., Li, F. B., Xia, Y. H., Zhang, G. Z., Li, H. J., 2017.

716 Bio-inspired layered chitosan/graphene oxide nanocomposite hydrogels with high strength and $\mathrm{pH}-$ 717 driven shape memory effect. Carbohydr. Polym., 177, 116-125.

718

719 Zhou, G., Liu, C., Tang, Y., Luo, S., Zeng, Z., Liu, Y., Xu, R.,Chu, L. 2015. Aerogel-like 720 polysiloxane-graphene oxide gel as a highly efficient and renewable adsorbent for lead and 721 cadmium metals removal from wastewater. Chem. Eng. J. 280, 275-282.

723 Zou, X., Zhang, L., Wang, Z., Luo, Y., 2016. Mechanisms of the Antimicrobial Activities of 724 Graphene Materials. J. Am. Chem. Soc. 138, 7, 2064-2077. 